\title{
ALGUNS PONTOS DE INTERROGAÇÃO SOBRE IDENTIDADE(S) E TERRITÓRIO(S) EM TARTESSOS
}

\author{
SOME QUESTIONS ABOUT IDENTITY(IES) AND TERRITORY(IES) IN TARTESSOS
}

\author{
PEDRO ALBUQUERQUE*
}

\begin{abstract}
Resumo: Este trabalho pretende testar a relevância dos conceitos modernos de Identidade, Etnia, Mestiçagem e Território na análise do registo arqueológico e das fontes escritas gregas que referem Tartessos entre os séculos VII e V a.C. Inicialmente, definem-se os conceitos, bem como um questionário centrado na comparação com a política colonial portuguesa em Angola e com a formação de Spirit Provinces na região de Cacheu (Guiné-Bissau). Esta análise permite colocar várias questões sobre os citados conceitos, enquadrando-os numa interpretação metodologicamente mais crítica dos registos escrito e arqueológico. Permite também ponderar, através da analogia com os exemplos africanos, a existência uma possível desconstrução das perceções territoriais indígenas em prol de uma nova ideologia dominante que edificou novos marcadores territoriais.
\end{abstract}

Palavras-chave: Identidade étnica; Território; Analogia etnográfica; Spirit Province; Fontes escritas; Registo arqueológico; Tartessos.

\section{INTRODUÇÃO}

Partindo da análise da documentação escrita e do registo arqueológico, este trabalho pretende colocar alguns pontos de interrogação sobre identidades e territórios em Tartessos. Sem perder de vista o percurso historiográfico do tema (entre outros, Álvarez 2005,

\footnotetext{
* Universidade de Lisboa. Faculdade de Letras. 1600-214. Lisboa (Portugal). Correo-e: skapedroalbuquerque@gmail.com
}

\begin{abstract}
This work aims to test the relevance of the modern day concepts of Identity, Ethnicity, Miscegenation and Territory in the analysis of the Archaeology and of the Greek written sources, which refer to Tartessus between the 7th-5th centuries BC. It begins by defining the concepts and some questions based on a comparative study involving Portugal's colonial politics in Angola and the construction of Spirit Provinces in the Cacheu region (Guinea - Bissau). This analysis ended up raising several questions regarding the use of concepts in a methodologically accurate interpretation of the data provided by the written and archaeological sources, as well as questions (by analogy with African examples) about the existence of a possible deconstruction of indigenous territorial perceptions by a new dominant ideology that constructs new territorial markers.

Keywords: Ethnic Identity; Miscegenation; Territory; Spirit Provinces; Written Sources; Archaeological Sources; Tartessus.
\end{abstract}

2009), apresenta-se uma breve discussão sobre os conceitos manejados, nomeadamente: Identidade (I), Etnia/Grupo Étnico, Etnicidade (II), Mestiçagem (III) e Território (IV).

Esta discussão faz parte de um trabalho mais amplo que incide sobre a interpretação das necrópoles e dos santuários de origem ou influência oriental no Baixo Guadalquivir como marcadores territoriais e, consequentemente, como elementos determinantes para a construção, reconstrução e desconstrução de identidades. A delimitação da área de estudo, bem como da 
cronologia (c. séc. IX-VI a.C.) deve ser vista como um ponto de partida para uma análise mais alargada. É deste modo que o trabalho que agora se apresenta pretende definir algumas bases para a colocação de perguntas, mais do que para a obtenção de respostas.

Para levar a efeito esta análise, optou-se pela leitura crítica da documentação escrita grega (sécs. VII-V a.C.) com base nos conceitos assinalados, por um lado, e em recentes contributos para a História de África, por outro. Estabelecendo alguns critérios de leitura, estes dois campos de estudo revelam-se importantes para uma proposta de análise do registo arqueológico.

Apesar de diferentes, as vertentes assinaladas apresentam importantes pontos em comum e colocam os mesmos problemas. A literatura grega (tal como a europeia sobre África que lhe é posterior) produziu representações que resultaram na construção de entidades cujas caraterísticas nem sempre são percetíveis. Boa parte, senão a totalidade, destas representações, diz respeito a uma realidade costeira ou das margens de um rio navegável, deixando de lado (por desconhecimento ou por desinteresse) comunidades que viviam no interior e que foram englobadas na mesma designação (Bühnen 1992: 45ss). Com a colonização em África, p.ej., registam-se casos óbvios de apropriação dessas categorias étnicas para o surgimento de novas identidades (Amselle e M'Bokolo 1999, Moret 2004, Henriques 2004).

A análise destes processos permite constatar, por um lado, que existe um grande desfasamento entre a realidade do observador e a realidade vivida ou sentida pelo observado. Por outro, que a identidade é um fenómeno que depende das circunstâncias históricas e sociais de um indivíduo ou de uma comunidade.

É neste sentido que devemos colocar a tónica na terminologia utilizada para descrever comunidades humanas nos dois âmbitos literários. Isso permite assinalar que os conceitos manejados na análise das chamadas Etnias pré-romanas são mais herdeiros das conceções coloniais europeias do século XIX do que, propriamente, da terminologia grega ou mesmo latina. Uma análise desta terminologia permite matizar alguns apriorismos e, consequentemente, é extremamente útil para uma aproximação aos critérios que presidem a uma designação étnica. A um cenário de unidade presente numa designação sobrepõe-se outro, marcado pela diversidade e, sobretudo, pela permeabilidade à mudança. Tal perspetiva obriga a uma leitura crítica das traduções das fontes escritas, sobretudo quando estas não permitem verificar o alcance do termo original, como veremos (cf. Heintze 2007: 126-128).
Outro dos aspetos que podem ser alvo de discussão é o impacte da presença colonial em África, mais concretamente na atual Angola. Este caso é interessante pelo facto de permitir colocar algumas questões sobre a noção de Território (e dos seus marcadores) como espaço manipulado pelo Ser Humano e como elemento de relação com a natureza e com outras comunidades. A presença colonial portuguesa implicou o desmantelamento de algumas estruturas que organizavam, consolidavam e mantinham as identidades dos grupos humanos que aí habitavam. Teremos oportunidade de assinalar os mecanismos desenvolvidos pelas comunidades residentes na adaptação a novas circunstâncias históricas e políticas, bem como a materialização destes processos.

Esta perspetiva destaca o papel das necrópoles e dos santuários como elementos determinantes na construção de identidades, como mecanismos de transmissão da história de um grupo humano e como símbolos da presença e/ ou domínio de um grupo. É por este motivo que a definição de Spirit Province, defendida por E. Crowley (1993), pode ser útil como ferramenta de análise para processos de imposição de uma ideologia dominante, sem que isso comprometa a diversidade de identidades em cenários de contacto e em espaços onde convivem grupos de origens muito variadas.

\section{IDENTIDADE}

Em termos gerais, a identidade é um aspeto do comportamento determinado por uma relação de afirmação (identificação) ou negação (identização) que o Ser Humano estabelece consigo mesmo e com os outros (Knapp 2008: 32). Dependendo da alteridade e, consequentemente, de uma representação justificada pelo contacto, a identidade pode ser egorreconhecida ou alteroadscrita (Terén 2002: 46). Afirmação e negação são dois elementos que se alimentam reciprocamente e, como tal, estão sujeitos a transformações consoante as exigências das circunstâncias históricas, sociais, políticas ou económicas de uma sociedade (Hernando 2002, Lalanda 2005).

Podendo também tratar-se de uma estratégia de sobrevivência e integração, a identidade acompanha o indivíduo num processo constante de imitação ou mimesis que lhe confere originalidade (Potolsky 2006: 115ss.). Como tal, uma personalidade individual ou coletiva estabelece critérios que a identificam e diferenciam de outras, criando com isto um filtro para a construção e reconhecimento de sentimentos de pertença ou de 
não-pertença que só fazem sentido quando estão sujeitos a uma circunstância determinada (Knapp 2008: 32). A identidade surge também como consequência de relações entre dominadores e dominados, fazendo com que possa ser um fenómeno histórico ou um "rapport de forces" (Amselle 1990: 54ss., Ruby 2006: 65). Em 1997, P. Jenkins propõe um "modelo sócio-antropológico da etnicidade", equilibrando o pensamento de M. Weber sobre a "diferença sentida", de G.H. Mead sobre a construção do Eu social e de F. Barth sobre a "organização social das diferenças étnicas"(segundo Terén 2002, Hernando 2002: 50ss.).

Permita-se-me apresentar um exemplo: a identidade dos Portugueses na Literatura é afirmada através da negação do Castelhano quando se tratava de garantir a independência (Albuquerque 2008, Knapp 2008: 32, Sousa e Santos 2010). Esta relação de negação deixava de fazer sentido a partir do momento em que o inimigo era o Muçulmano, assistindo-se a uma união baseada no critério da religião (Cristãos). Do mesmo modo, o

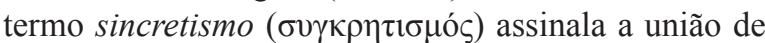
dois cretenses contra um terceiro (Plu., Moralia 490b).

É também no cenário da guerra contra os Persas que surge a identidade grega (Cardete 2004: 19ss., com bibliografia), uma vez que a presença de uma entidade exterior criou as condições necessárias para a construção de uma união de vários grupos em torno de uma designação comum. Estes estão, claramente, expostos por Heródoto (7.144.2) quando apresenta alguns critérios que estruturam esta unidade ( $v$. Hdt. 1.142-148). A uma ideia de consanguinidade acrescenta-se uma unidade ao nível da língua. Os usos e costumes daqueles que integram este grupo alargado são similares, mas não necessariamente os mesmos. Para além disso, Heródoto assinala uma comunidade de santuários e de sacrifícios aos deuses. Apesar de o nome "Grego" (definidor de um conjunto de grupos diferentes entre si) colocar alguns problemas (Cardete 2004: 20-24), as invasões persas sustentaram, em boa medida, esta afirmação, confirmando a ideia, anteriormente exposta, de que a identidade é um processo que resulta de uma representação. Ou seja, é a alteridade que confere sentido a uma autoafirmação, resultando daí a polarização Gregos/

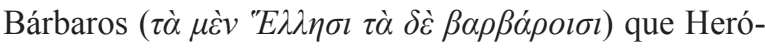
doto apresenta no prólogo da sua obra (sobre o conceito de Bárbaro, cf. Dubuisson 2001).

Estes exemplos permitem destacar a importância da linguagem na construção dos nomes (nome próprio, dos pais, família, cidade, região) que estruturam a identidade de uma personalidade individual e coletiva (Amselle 1990: 65), como resultado da interação de vários fatores que a individualizam e que determinam a auto e a heteroperceção (Dias 1999, García 2009). Ou seja, um nome exprime um significado, o que se aplica, p.ej., à toponímia (cf. Sanmartín 1994). Permitem também assinalar que a construção do Outro assenta sobre os critérios que o Eu utiliza na sua autoperceção (língua, rituais, sacrifícios, alimentação, sistemas sociais, posição social, etc.) e que nem sempre requerem um antepassado comum (cf. Escacena 1992, Bourdieu 2011: 57ss., Od. 8.572-576, Hdt. 8.144.2, Th. 1.8.1).

Estes breves apontamentos são importantes para afirmar que a identidade é, essencialmente, um fenómeno histórico cujas transformações nem sempre são percetíveis. Consequentemente, torna-se claro que uma perspetiva essencialista é insuficiente para explicar a complexidade desta questão, não só em termos individuais, mas também em termos coletivos. Uma vez que o alvo desta contribuição é Tartessos, penso que é pertinente desenvolver alguns aspetos das identidades étnicas.

\section{ETNIA/GRUPO ÉTNICO}

Para García Martínez (2004: 141),

[...] la etnicidad no es sólo un asunto del tipo de la auto-identidad que siente la gente, sino también el tipo de identidad social atribuida por los otros. Así sucede en ocasiones que las mayorías no suelen atribuirse tales rasgos, pero los proyectan en las minorías, que serían las únicas poseedoras de etnicidad, con lo que habitualmente los miembros de los grupos dominantes se "olvidan" de considerarse a si mismos como un "grupo étnico".

O uso atual do conceito de Etnia ou Grupo Étnico reveste-se de alguma controvérsia pelo facto de nascer em contextos coloniais, como oposição ao conceito de Nação. Este primeiro aspeto conduz a uma necessidade de rever alguns princípios que estão na base da sua elaboração, ao mesmo tempo que contrastando o seu conteúdo com o de ع̋ $\theta v o \varsigma$ na língua grega. Atendendo às ocasiões em que Etnia descreve um grupo humano, verificamos que se aplica a um grupo minoritário (p.ej., etnia cigana) ou a grupos que entram em conflito dentro de um mesmo Estado (em países africanos). Talvez por este motivo, عै $\theta v o \varsigma$ (ethnos) raramente é traduzido por etnia, o que também se justifica pelo facto de o termo grego não ter o conteúdo racial que reveste o conceito a partir do séc. XIX (Cabanes 2005: 850, Amselle e M'Bokolo 1999). 
Neste contexto, importa dar um especial destaque a algumas ocasiões em que $\varepsilon_{\theta} \theta v o \varsigma(=\ddot{\varepsilon}$.) surge na literatura grega, começando pelos Poemas Homéricos. Nes-

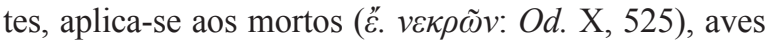
(č. ó $\rho v i \theta \omega v$ : Il. 2.459), abelhas (है. $\mu \varepsilon \lambda \lambda l \sigma \sigma \dot{\alpha} \omega v:$ Il. 2.87),

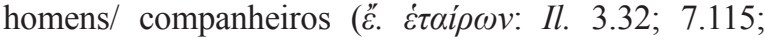
11.595 , etc.), grupos humanos alargados (p.e Aqueus/ है.

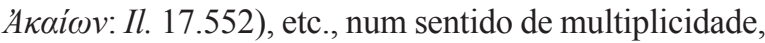
grupo, comunidade ou conjunto sem uma conotação cultural, traduzindo-se por "raça", "tribo", etc. (cf. Cardete

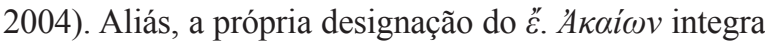
as várias comunidades individualizadas que são assinaladas no Canto II da Ilíada.

Este sentido de conjunto está também presente na obra de Heródoto, mas neste caso refere-se, exclusivamente, a grupos humanos (cf. Powell 1938: 98-99). O seu discurso, como aponta C.P. Jones (1996: 315), não costuma tratar com detalhe os conceitos que utiliza, provocando no leitor atual alguma confusão relativamente ao significado de termos como ét $\theta v o \varsigma$ e $\gamma^{\prime}$ v́vos. Apontemos alguns exemplos.

Heródoto apresenta Creso como "rei dos Lídios e de

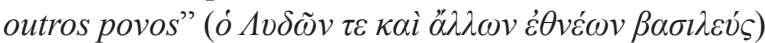
em 1.53.2, deixando entrever que $\varepsilon^{\prime}$. nem sempre está associado a uma comunidade específica e que pode ter uma conotação de aliança política (Cruz 2010: 20). Por

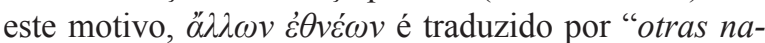
ciones" (C. Schrader). Esta situação repete-se ao longo do texto herodotiano (1.69.1- 2, 171.3, 177, etc., cf. Powell 1938). O mesmo ocorre com a representação de

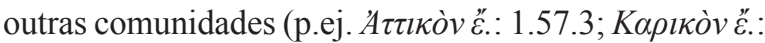

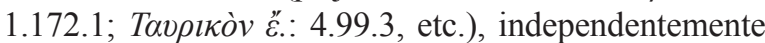

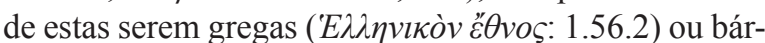
baras ( $\dot{\varepsilon} \theta v \varepsilon ́ \omega v \beta \alpha \rho \beta \alpha ́ \rho \omega v: 1.58)$. Esta variedade parece colocar algumas dificuldades de tradução (p.ej. है' $\theta v o \varsigma$, tribo em 4.71.1 e 171, e povo em 4.197.2). Neste último caso, trata-se de uma referência aos povos autóctones (Líbios e Etíopes) e estrangeiros (Fenícios e Gregos)

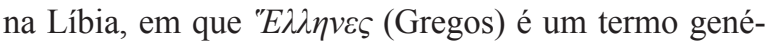
rico independente da origem dos colonos. No primeiro, tomando como exemplo a tradução de C. Schrader, o termo é traduzido por "tribo" e "povo" na mesma passagem. Acrescenta-se ainda o uso de termos compostos como $\dot{\mu} \mu \varepsilon \theta v \varepsilon ́ \omega v$ (i.e., "do mesmo povo") numa ocasião (1.91.5).

Por outro lado, o termo $\gamma$ ćvos (génos, $=\gamma$.) parece designar em Heródoto grupos unidos por consanguinidade, daí a sua relação com "nascimento", "linhagem", "família", "estirpe", "ascendência/descendência" e, eventualmente, com "raça" ou "Nação" (Chantraine

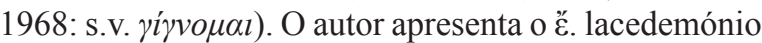

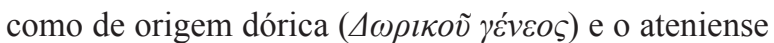

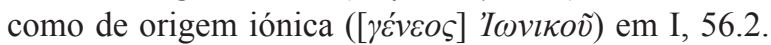
A este respeito, M.C. Cardete (2004: 18) comenta que este sentimento de identidade, transmitido pelo termo Ëtvos, "en ocasiones se confunde con el genos, entendido también en un sentido muy amplio tanto como el mecanismo por el que uno accede a una identidad que como el grupo que la proporciona. Heródoto, por ejemplo, utiliza ambas palabras para referirse a realidades idénticas". Exemplo disso é a referência aos

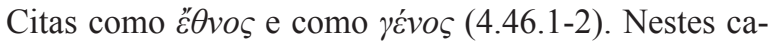
sos, $\gamma$. designa uma entidade que integra vários povos unidos por um antepassado comum (p.ej., 1.143.2; 4.46.2; 5.91.1; 7.185.2), bem como espécies de animais (1.159.3; 3.113.1; 4.29, Jones 1996: 315ss.).

Para além disso, em 5.2.2, Heródoto faz uma distinção (pouco frequente na sua obra) entre ét $\theta v o \varsigma$ e $\pi o ́ \lambda l \varsigma$, referindo-se às campanhas de Megábaso, que submeteu à autoridade de Creso todas as cidades e todos os povos ( $\pi \tilde{\alpha} \sigma \alpha v \pi o ́ \lambda l v \kappa \alpha i ̀ \tilde{\alpha} v \tilde{c} \theta v o \varsigma$ ) da Trácia (cf., igualmente, 6.27.1; Arist., Pol. 2.2/1261a; 3.19/1284a). Os trácios, segundo o autor (Hdt. 5.3.1), são o segundo povo mais numeroso da terra e são apresentados como um ě $\theta v o \varsigma$ sem unidade política que se divide em várias "tribos".

Os exemplos assinalados permitem verificar que $\varepsilon ̋ \theta v o \varsigma$ é um termo que adquire vários sentidos. A sua aplicação nestes contextos aconselha a ter alguma cautela, na medida em que não exclui cenários de diversidade. Adiantando parte das reflexões gerais deste trabalho, o sentido do conceito grego, quando aplicado ao étvoऽ "Tartéssio", pode refletir realidades muito diversificadas, com contornos que variam ao longo dos tempos (cf. Álvarez 2009).

Apesar de se manter um sentido de grupo humano ou, se preferirmos, de um conjunto de indivíduos unidos em torno de um sentimento de pertença e, que através dele, se individualizam face a outro (cf. Gonçalves e Barata 1999: 1311, Hillmann 2001: 330-331), o uso científico de "Etnia" resulta de um processo que pode e deve ser questionado no seu alcance ideológico. A crítica nasce das retrospetivas "africanizadas", que destacaram o uso atual do termo como um produto do racismo europeu do séc. XIX (Amselle e M'Bokolo 1999, Moret 2004, Ruby 2006, Fernández 2009), a tal ponto que Etnia ou Grupo Étnico podem ser sinónimos de Raça (Bernal 1993: 115- 116, Gaulmier 1981), não obstante a gradual perda de importância do último. Por outras palavras, pode entender-se o conceito de Etnia como

[...] communauté de langue, de coutumes, de valeurs et souvent, mais pas nécessairement, de cultes; 
implantation dans un espace ou un territoire défini ; conscience d'appartenir à un même groupe (ce qui implique, le plus souvent, la revendication d'une ancêtre commun ou pour le moins d'une affinité de sang) ; existence d'un nom désignant de ce groupe (Moret 2004: 34).

Atendendo ao panorama da obra de Heródoto, é possível assinalar a grande variabilidade destes sentimentos de pertença em torno da língua, dos costumes, dos valores ou mesmo dos cultos (cf. infra)

Os conceitos de "Raça" e "Etnia" começaram a ser utilizados a partir do século XIX, substituindo termos como "Reino", "Nação" e "Região", que faziam parte dos relatos de viagem anteriores (Amselle e M'Bokolo 1999: 70ss.). A organização dos territórios coloniais acabou por justificar a ascensão de uma terminologia que marcava uma diferença entre o selvagem e o civilizado, ao mesmo tempo que exprimia o desmantelamento das estruturas políticas anteriores, com uma cada vez maior compartimentação dos reinos africanos (Amselle 1987: 469).

Esta situação conduz a um exemplo que deve ser destacado: a elaboração dos mapas étnicos em África segundo os critérios do poder colonial. Estes, em última análise, refletem o modo de pensar do colono e nem sempre as estratégias de individualização das comunidades representadas, o que aliás é visível na elaboração da obra As Raças do Império, de Mendes Correia e nas dificuldades que os observadores sentiram na definição de critérios de individualização, fundamentais na elaboração destes "mapas étnicos" (Estermann 1983: 17ss., Amselle 1987, Henriques 2004: 72-3). A título de exemplo, o Atlas de Portugal Ultramarino, publicado em 1948, baseou-se na divisão linguística e esta, em muitos casos, não fazia qualquer sentido (Esterman 1983: 17). Do mesmo modo, outros critérios produziriam mapas diferentes, transmitindo uma ideia de unidade cultural que nem sempre corresponde aos mecanismos de identificação das comunidades representadas.

Assim, nas palavras de R. Batty (2000: 92), “...one cannot use a subway map in the same way as an Atlas. The former tells you how to get somewhere. The latter tells you how to think about, locate and separate human communities. It embodies a way of thinking".

A análise dos exemplos africanos constitui, deste modo, um desafio às nossas perceções e, consequentemente, ao alcance dos critérios que utilizamos para definir os limites de Tartessos.

Quer isto dizer que nem sempre é possível determinar quais as senhas de identidade utilizadas por um grupo para se individualizar perante outro (Jones 1997: 74, Knapp 2008: 37), sobretudo quando as circunstâncias dos contactos são pouco ou nada conhecidas. Por outras palavras, há que determinar qual o tipo de relação que as comunidades têm entre si para verificar se há, ou não, necessidade de desenvolver uma estratégia de individualização e quais os critérios para levá-la a efeito. Por outro lado, há que considerar a discussão em torno da génese de um sentimento/relação de pertença (Wulff 2005) e a elaboração de modelos que procuram explicar a Etnicidade ("le caractère ou la qualité d'un group ethnique", segundo P. Ruby 2006: 32, 39-40, cf. Jones 1997: 56ss., Bentley 1997: 26, Terén 2002: 47.3, Cardete 2004: 19, Knapp 2008: 36-37, Fernández 2009: 190).

Esta questão conduz a outra não menos importante: a formação dos nomes de grupo. Uma mesma comunidade pode ter quatro (ou mais) nomes diferentes: o nome com o qual o grupo se designa a si mesmo; o nome dado pelos vizinhos; o nome dado por um observador externo em relação a 1 e 2 (viajante, colonizador, etc.) e, finalmente, o nome que é transmitido pelos informadores deste último (Crowley 1993: 280-284). Assim, o nome pelo qual conhecemos uma comunidade nem sempre é reconhecido ou utilizado por esta, como parece ser o caso dos Bosquímanes, etnónimo criado pelos colonos Holandeses do Cabo (Bosjesmannen; ing. Bushmen) para designar um grupo de "homens da floresta" (Estermann 1983: 35); esta designação, notese, baseia-se na observação de uma diferença.

Esta ideia deve, porém, ser matizada, uma vez que, tanto no caso africano como no caso das populações mencionadas durante o domínio romano, assinala-se, "d'une part, l'émergence ou la consolidation des ethnies comme conséquence de l'entreprise coloniale; d'autre part, la réappropriation par les populations indigènes elles-mêmes des catégories ethniques imposées depuis l'extérieur" (Moret 2004: 35, García 2007: 124125). Noutros casos, assiste-se também a processos de desidentificação (Crowley 1993: 284).

A ideia de "unidade cultural" acaba por estar presente na elaboração destes mapas e nas perspetivas de análise do registo arqueológico. Esta ideia refletiu-se no critério da materialidade como mecanismo de reconstrução paleoetnológica (Ruby 2006, Niculescu 1997-1998; Jones 2008: 321, Fernández 2009), partindo do princípio de que uma cultura material equivale a um povo. Esta perspetiva tipológico-comparativa parece estar patente em Tucídides (1.8.1) quando refere os enterramentos dos Cários (cf. Ruby 2006: 28-29) no contexto da “purificação de Delos" por Pisístrato (Hdt. 1.64). Neste 
sentido, criou-se também a ideia de que os rituais funerários eram marcadores étnicos estáveis (Niculescu 1997-1998: 203-204).

Tartessos, como teremos oportunidade de ver, é um nome que não apresenta grande unidade de sentidos na documentação escrita. A polarização de entidades (Indígenas/Tartéssios e Fenícios) pode não fazer sentido quando a comparamos com o conceito de $\varepsilon$ $\theta v o \varsigma$ na língua grega. A identificação de um etnónimo num documento escrito grego não implica que o grupo representado tenha uma unidade cultural ou linguística ou que seja puro ao ponto de justificar uma polarização rígida. É por este motivo que podemos abordar, de forma breve, a questão da mestiçagem.

\section{MESTIÇAGEM}

Ao descrever os Iónios, Heródoto afirma que

[...] desde luego es una solemne estupidez pretender que éstos son más jonios que los demás jonios o de más noble origen, dado que, entre ellos, hay un núcleo no despreciable de abantes de Eubea, que nada en común tienen con Jonia, ni siquiera el nombre; también hay mezclados con ellos minias orcomenios, cadmeos, driopes, focenses disidentes, molosos, árcades pelasgos, dorios epidaurios y otros muchos pueblos [...] (1.146.1; Trad. C. Schrader).

Nesta descrição (1.142ss.), o autor assinala que um $\varepsilon$ $\theta v o \varsigma$, no sentido geral, pode ter dentro de si outros $\varepsilon^{\prime} \theta v \eta$, bem como uma ideia de mistura que acaba por estar presente na terminologia grega (Dubuisson 1982). Mais adiante, apresenta o exemplo dos Budinos: no território deste ě $\theta v o \varsigma$ ter-se-ão estabelecido gregos oriundos dos empórios marítimos do Ponto Euxino, fundando a cidade de Gelono e estabelecendo aí santuários consagrados a deuses gregos, com altares e imagens de modelo igualmente grego. Heródoto regista, porém, uma diferença em relação a arquitetura, uma vez que os santuários são construídos em madeira, à semelhança dos Budinos. Apesar de se manter uma certa identidade grega, os habitantes de Gelono falam uma língua "meio cita, meio grega" (4.198) e estão integrados no é $\theta$ vos dos Budinos.

O exemplo dos cipriotas parece ser também ilustrativo: "[...] según el testimonio de los propios chipriotas, entre ellos hay elementos étnicos procedentes de todos estos países: de Salamina y Atenas, de Arcadia, de Citnos, de Fenícia y de Etiopía" (Hdt. 7. 90). Como podemos ver, estes grupos de outsiders são integrados numa mesma designação numa determinada ocasião, podendo abandoná-la em prol de uma identificação mais conveniente para os seus interesses (Crowley 1993: 284-285). O caso dos Luso-africanos é também expressivo neste sentido, uma vez que nesta designação integram-se indivíduos de origens (locais e externas) muito diversificadas (Horta 2009: passim).

Esta ideia de mistura é entendida, em parte, pelo termo mestiçagem (ou mestiço), que pressupõe a definição de dois elementos, entendidos como antagónicos, que se misturam (Twisselmann 1971). O termo mestiço (ou misto) referia-se, primeiramente, a uma opção política, designando grupos de Cristãos que se uniram aos Muçulmanos na luta contra o rei Rodrigo (Bernand, apud Gruzinski 1999: 36-37 e n. 11). Deriva do latim mixtu, i.e., misturado. Este termo, por sua vez, deriva do grego $\mu l \xi$ ou $\mu \varepsilon l \xi$ - (p.ej., $\mu l \xi \xi \dot{\varepsilon} \lambda \lambda \eta v \varepsilon \varsigma$ de Plb. 1.67 .7 e $\mu l \xi o \beta \alpha ́ \rho \beta \alpha \rho o \varsigma$ de Pl., Mx. 245d; X., HG II, 1.15; E., Ph., 138).

O Novo Dicionário da Língua Portuguesa assinala, precisamente, o sentido biológico desta terminologia: (a) mestiçagem: 1. "Cruzamento de raças diferentes". 2. "Reprodução de mestiços entre si"; (b) mestiçar: "cruzar etnias diferentes ou indivíduos da mesma etnia com os de outra, gerando mestiços"; (c) mestiço: "aquele que tem pais de etnias diferentes entre si".

Esta questão mereceu atenção em estudos sobre o papel da hibridação ou dos matrimónios mistos na criação de novas realidades culturais na América. Estes processos irreversíveis, ideológica e tecnologicamente, mudaram por completo a relação das comunidades autóctones com o ambiente que as rodeava, provocando uma "europeização" dos Americanos e a "americanização" dos Europeus (Gruzinski e Bernand 2007: 617). Estas transformações realizam-se "selon les rythmes et des chronologies qui s'accordent mal à notre vision linéaire de l'histoire » (ibid.: 618).

Embora este tema não possa ser desenvolvido com maior detalhe, gostaria de assinalar um aspeto que tem implicações na leitura do registo arqueológico: de acordo com a leitura de S. Gruzinski e C. Bernand (2007: 622),

La généralisation des métissages accoutume les individus et les groupes les plus exposés a circuler entre les cultures et ls modes de vie. Ces va-et-vient développent une sensibilité culturelle à la différence, une aptitude à varier les registres, tout comme ils stimulent la capacité à mêler ou a multiplier les masques et les appartenances.

Estas situações podem provocar aquilo que os autores apelidam de "mobilidade de identidades" 
(cf. Horta 2009), tornando difícil adquirir uma visão suficientemente clara do modo como essas diferenças são percebidas nas sociedades que procuramos analisar e como elas dão origem a novos processos, novas ideias, etc. (Arruda 2010).

Entendido como "un passage de l'homogène et l'hétérogène, du singulier au pluriel, de l'ordre au disorde" (Gruzinski 1999: 36), a mestiçagem pode aplicar-se às vertentes biológica e cultural do Ser Humano, respondendo a uma noção de pureza que justifica um hábito intelectual polarizante que deve ser matizado. Neste sentido, alguns trabalhos importantes colocaram o acento tónico na mestiçagem como ferramenta para a explicação de determinados processos de transformação (González 1989: 159ss., Bandera e Ferrer 1995). Este hábito intelectual polarizante foi duramente criticado por J.L. Amselle (1990: 9), que, num importante estudo sobre os chefados Peul, Bambara e Malinké (SW do Mali e NW da Guiné) apresenta uma alternativa que consiste numa aproximação "continuiste qui à l'inverse mettrait l'accent sur l'indistinction ou le syncrétisme originaire" (Amselle 1990: 9-10). Outras perspetivas, como a de F. Laplantine e A. Nouss, devem também ser assinaladas: "le métissage est une composition dont les composantes gardent leur integrité" e "le métissage n'est pas la fusion, la cohésion, l'osmose, mais la confrontation et le dialogue" (apud Gruzinski 1999: 38).

Considerando o "syncrétisme originaire" de Amselle, qualquer sociedade (ou qualquer indivíduo), num determinado momento, é o resultado de várias influências que produzem o resultado original que sustenta a identificação ou a identização. Deste modo, importa perceber a Cultura como um "ensemble de pratiques internes ou externes à un espace social donnée que les acteurs sociaux mobilisent en fonction de telle ou telle conjoncture politique" (Amselle 1990: 13). A conjuntura política e social, válida num determinado momento, pode desencadear a oposição entre duas entidades (p.ej., colonos e indígenas) que se excluem mutuamente, embora possam revelar sinais de interpenetração, convergência e até mesmo identificação (Gruzinski 1999: 39-40).

Quer isto dizer que a mestiçagem vai muito mais além de uma "fusão" no sentido biológico do termo, podendo ser abordada como um fenómeno de confrontação, diálogo, adaptação ou apropriação (Gruzinski 1999: 38) que incide sobre o património imaterial de uma sociedade, produzindo novas identidades. Não podemos também ignorar o papel dos matrimónios no estabelecimento de alianças políticas e na transmissão de informações (p.ej., 1Rs., 16, 29-33; Sil. 3.97-107). Um indivíduo pode representar a confluência de dois modos de vida distintos, fazendo com que exista uma necessária interpenetração de culturas nas linhagens de indígenas e orientais, a tal ponto que, a longo prazo, se torna difícil distinguir, arqueologicamente, uns de outros (Arruda 2010: 443ss.).

Apesar do interesse desta perspetiva, a imposição de uma ideologia dominante é um tema que importa destacar, tanto mais que permite uma aproximação a processos de violência que podem caraterizar as relações sociais. Estes processos são percetíveis, p.ej., na construção social do território.

\section{TERRITÓRIO E SPIRIT PROVINCE}

De acordo com I. Castro Henriques (2004: 20), o Território

[...] É o espaço necessário à instalação das estruturas e das colectividades inventadas pelos homens, sendo também indispensável à criação, manutenção e reforço da identidade. [...] É sempre simultaneamente o invólucro [...] e o suporte físico, espiritual e identitário das sociedades e das suas relações com as naturezas e os outros.

Esta definição surge no âmbito de um trabalho sobre a construção de identidades na Angola colonial, no contexto de um processo histórico que dará origem a um país independente. $\mathrm{O}$ exemplo de Angola, como veremos, permite definir um questionário importante para o estudo da presença fenícia na Península Ibérica e das suas relações com as comunidades residentes.

A cartografia, através da qual concebemos o espaço, é apenas uma entre várias formas possíveis de representação ou abstração (um exemplo n'Os Lusíadas, de Camões, em Albuquerque 2008: 153ss.). Atendendo a este aspeto, a existência de marcadores territoriais é também uma forma de conceber e apreender o espaço, o mundo habitado e a fronteira entre o território do Eu e o território do Outro. A organização simbólica e social do território materializa-se na construção de marcadores que exprimem a história e a identidade de uma comunidade (p.ej. Nordman 2005, Black 1997: 239); podem, consoante as relações intercomunitárias, desempenhar a função de marcadores de fronteiras (cf. Castro e González 1989: 10ss., Henriques 2004, García 2007). Inevitavelmente, a construção social de um território é etnocêntrica e responde a várias finalidades consoante a circunstância histórica em que se inscreve (Black 1997: 239-240). Este comentário estende-se à 
organização do discurso geográfico (p.ej. Batty 2000: 88-89). Creio que este discurso exprime uma relação histórica e identitária com o mundo habitado e, consequentemente, com um território concreto (cf. Henriques 2004).

Como símbolos da história de um grupo humano, os marcadores territoriais estão frequentemente associados a relatos de fundação. Estes, por seu turno, são um ponto de partida útil para a análise das relações sociais criadas a partir do momento em que uma nova entidade (p.ej., os fundadores de Gadir) ocupa um território, simbolizando a sua presença com um espaço de culto e uma cidade. Nesta perspetiva, o colonizador é aquele que, num determinado período de tempo, não tem os seus mortos enterrados nesse território, o que obriga à construção de uma nova história a partir da qual fabrica a sua identidade e legitima a sua presença. Creio que, nesse sentido, Melqart desempenha uma função fundamental como antepassado que, em tempos remotos, teria estado naquele lugar no contexto de um ciclo de destruição de seres ctónicos.

Estes processos trazem consigo novas perceções e estratégias de ocupação/ exploração do território, conduzindo muitas vezes ao choque de interesses entre as entidades envolvidas (Moreno 1999, González 2005, Henriques 2004, Albuquerque 2010: 53, n. 83). Abordando deste modo a implantação de necrópoles, espaços de culto e habitacionais, bem como a sacralização de espaços naturais (rios, colinas, etc.), é possível propor um modelo de análise que permite explicar processos de transformação no seio das comunidades residentes.

É neste sentido que podemos colocar um acento tónico na construção da Angola colonial. Antes do início deste processo, o território era ocupado por comunidades com "percursos históricos complementares" que o organizavam segundo as suas próprias "lógicas civilizacionais" (Henriques 2004: 9-10). Essa organização passava por uma complexa rede de marcadores territoriais que garantiam a coesão identitária dessas comunidades (Henriques 2004: 53-66). Apercebendo-se disso, o agente colonizador optou por desmantelar, progressiva e violentamente, essas estruturas para impor o seu sistema de organização política e económica do território. Esta atitude foi fundamental para o exercício (in)direto do poder colonial (cf. Amselle 1999: 153ss.).

Aspetos como a posse de terra e os marcadores territoriais que recordavam heróis fundadores (árvores sagradas, necrópoles, etc.) e assinalavam fronteiras e caminhos, acabaram por ser desmantelados e destruídos. Para o colono, a terra é um valor alienável; para o colonizado, é um elemento sagrado que condiciona a vida comunitária e os seus rituais: a terra é habitada e gerida por forças religiosas, estabelecendo-se com ela uma relação simbólica "indispensável à criação, manutenção e reforço da identidade" (Henriques 2004: 20) e da sua história.

Isto resultou, por um lado, no choque entre conceitos antagónicos (usos sociais e religiosos, ocupação/ organização/ controlo do espaço, marcadores simbólicos que identificam o território, etc.) e, por outro, numa reação (no lado indígena) no sentido de garantir a sobrevivência de alguns esquemas ancestrais, ao mesmo tempo que procurava reforçar a sua autonomia através da adaptação de elementos de origem colonial às estruturas preexistentes. Este processo é indissociável de algumas elites locais que, em determinadas ocasiões, defenderam o estatuto inferior do Negro, definido pela entidade colonizadora, para reforçar o seu poder. Segundo I.C. Henriques (2004: 83-87), registou-se uma apropriação de sistemas comportamentais e ideológicos (obtenção de lucro e aquisição/ acumulação de riquezas, concorrência, etc.), técnicos (agricultura, artesanato e arquitetura) e simbólicos (representação do mundo), bem como a escrita e a estética do corpo (vestuário, recusa da nudez e de outros elementos externos ao corpo como, p.ej., tatuagens).

A materialização deste processo permite questionar até que ponto as transformações que são assinaladas no contexto indígena peninsular na I Idade do Ferro podem refletir reações adaptativas resultantes dos novos modelos impostos pelas comunidades orientais e da referida necessidade de "escrever" uma nova história num território. Neste sentido, podemos assinalar possíveis processos de "dessacralização" ou "ressacralização" de um território.

O epidódio da purificação de Delos parece assinalar a importância de uma necrópole como marcador territorial e símbolo de uma identidade de grupo (Th. 1.8.1; Hdt. 1.64.2) e permite uma comparação interessante com o desmantelamento dos marcadores em Angola. Do mesmo modo, o Antigo Testamento assinala processos similares (p.ej., 2Rs. 23; Dt. 12, 1-3) de destruição de símbolos associados a uma comunidade com o intuito de apagar a sua memória num determinado espaço. O mesmo pode ser dito em relação aos santuários, que em muitos casos simbolizam um episódio histórico, implantando-se em lugares previamente ocupados (p.ej. Caura: Escacena 2001).

Estes processos acabam por conduzir à elaboração de mecanismos de integração e exclusão ou, se preferirmos, de "fronteiras sociais" (García Fernández 2007). 
A implantação de estruturas que simbolizam o domínio de um grupo sobre os outros é um tema fulcral para a construção de Spirit Provinces. Este conceito, desenvolvido por Eve Crowley (1993: 215ss.) num estudo sobre a região de Cachéu (Guiné- Bissau), aplica-se a um território composto por comunidades diferentes que se unem em torno de uma ideologia dominante. Apesar de não pressupor a existência de uma estrutura política centralizada, uma SP cria mecanismos que a diferencia de outras, integrando indivíduos de origens muito diversificadas num mesmo sentimento de pertença: "each spirit province became a local frontier, with an unusually fluid and mobile social organization capable of accomodating outsiders in a variety of ways" (ibid.: 223).

Não obstante as necessárias matizações deste conceito quando aplicado ao registo arqueológico da Península Ibérica, a sua utilidade reside no facto de permitir uma análise que valorize a diversidade, sobretudo quando parece evidente que a expansão oriental era composta por grupos oriundos de vários quadrantes do Mediterrâneo e não somente de Tiro (cf. Belén e Escacena 1995: 68-69, González 1989: 144, 2000), apesar do vínculo estabelecido com a cidade de origem (Str. 3.5.5; Bordreuil e Ferjaoui 1988; López 2004). Para além disso, a implantação de marcadores territoriais como os santuários é um aspeto que pode, e deve, ser valorizado na análise dos referidos processos de "orientalização" das comunidades residentes e de "ocidentalização" dos orientais (Escacena 2011). Creio que um dos sintomas mais evidentes de adaptação a novas realidades é a variedade das manifestações de Astarté ao longo do Mediterrâneo (Bonnet 2010). Em todo o caso, a construção de uma Spirit Province permite uma integração e um domínio eficazes quando centralizada num santuário.

\section{BALANÇO E PERSPETIVAS}

Atendendo ao exemplo de Angola, as transformações das comunidades residentes podem ser analisadas numa perspetiva arqueológica, sobretudo quando se segue o critério da visibilidade dessas manifestações materiais (p.ej., Henriques 2004, Knapp 2008: 34-35). A arquitetura, os rituais, um tipo de vestuário ou adorno, etc., só são elementos de afirmação identitária quando se destinam a ser visíveis perante a comunidade ou perante outras, e podem não desempenhar as mesmas funções nos sítios onde são identificados. Numa passagem de Heródoto é possível identificar um exemplo de objeto que é utilizado para afirmar a identidade de um grupo (IV,3.4): os chicotes dos cavalos, fundamentais para identificar os senhores perante os seus escravos:

[...] En las presentes circunstancias soy de la opinión de dejar a un lado picas y arcos, y de marchar a su encuentro provistos cada uno de nosotros del látigo de su caballo. Pues, mientras nos verían con las armas en la mano, creían ser iguales a nosotros y de nuestra misma alcurnia; pero, cuando nos vean con látigos en lugar de armas, comprenderán que son nuestros esclavos y, en ese convencimiento, dejarán de ofrecer resistencia (trad. C. Schrader)

Do mesmo modo, os objetos descritos nos Poemas Homéricos podem estar associados à imagem do herói e das suas extraordinárias riquezas. Acrescentado os exemplos de Dt. 12, 1-3 e 2Rs. 23, os santuários, os altares e as necrópoles são elementos visíveis da identidade de um determinado grupo, o que justifica a sua destruição.

A identidade, como construção social em permanente manipulação, resulta de circunstâncias históricas que nem sempre podem ser definidas arqueologicamente. A hierarquização social é somente um dos patamares possíveis da identidade, e mesmo assim pode não afetar a identidade de um grupo como um todo. Neste contexto, os comportamentos funerários podem ser um mecanismo de identificação ou identização de uma comunidade ou grupo social, operando por vezes (como no caso de Heródoto), como filtro de representação (Soares 2003).

Vimos que a identidade, como construção social, afeta âmbitos diferenciados consoante as circunstâncias históricas que rodeiam a criação, manutenção ou consolidação de grupos identitários dentro de uma comunidade, ou de uma comunidade perante outra. A hierarquização social é um entre vários critérios de diferenciação mas, noutra perspetiva, haveria que questionar se estas manifestações afetam (ou não) a identidade desse grupo como um todo. Por seu turno, a língua nem sempre é um critério válido de diferenciação, uma vez que pode ser comum a comunidades que se consideram como diferentes (cf. Estermann 1983: 17-19, 22, Henriques 2004: 72-3). A implantação de uma Spirit Province, para além de integrar uma grande diversidade de grupos sociais, línguas, etc., é um mecanismo útil no controlo da reprodução social, uma vez que é dentro destas que se contraem matrimónios mistos (Crowley 1993: 222ss.). É este suposto cenário de diversidade que pode ter caraterizado a gradual implantação de uma ideologia oriental, embora adaptada, no SW peninsular. 
Todas as questões colocadas podem ser aplicadas à construção da(s) identidade(s) de Tartessos. A perspetiva essencialista que marcou boa parte dos estudos que se debruçaram sobre o tema (cf. Álvarez 2009) impôs uma polarização que pode não ser viável quando analisamos com maior profundidade a variedade de situações

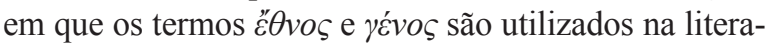
tura grega. Ou seja, o facto de se mencionar, implícita ou explicitamente Tartessos como um território pertencente a um $c^{\prime} \theta$ vos (Tartéssios) a partir do séc. VII a.C., não implica que essa comunidade seja puramente indígena ou fenícia, ou que fale uma mesma língua. Pode tratar-se de um grupo misto, tal como os cipriotas (Hdt. VII.90), mas que partilha uma mesma designação ou, simplesmente, de uma designação genérica cujo conteúdo nem sempre é percetível aos nossos olhos. Atendendo às palavras de M. Álvarez Martí-Aguilar (2009: 92):

[...] En lo relativo a la cuestión de la identidad hay que preguntarse sobre el significado de los tartesios del texto iSon, simplemente, los habitantes de Tartessos, esto es, los súbditos de Argantonio, y no existe un contenido étnico-endógeno- tras esta denominación? ¿O bien los tartesios son un colectivo, un ethnos, definido por un común sentimiento de pertenencia expresada en ese nombre? ¿O ambas cosas?

Podemos apontar várias questões à formação de etnónimos ou de topónimos, uma vez que as representações transmitidas nos relatos de viagem ou nos discursos geográficos raramente ultrapassam a linha da costa ou o interior dos rios navegáveis (J., Ap. I, 6068, Bühnen 1992). Para além disso, como se assinalou, um grupo humano pode ter vários nomes consoante as circunstâncias (Crowley 1993: 280-284) e, na maioria dos casos, estas designações revelam um grande desfasamento entre a realidade observada pelo agente externo e a realidade vivida pela população representada. Neste sentido, podemos assinalar as citadas questões colocadas por M. Álvarez (2009: 92) ao texto herodotiano e a reflexão de $\mathrm{M}$. Koch, quando afirma que uma aproximação a estas representações "...exige determinar los conocimientos geográficos sobre la Península de los que se disponía en cada una de las épocas en las que estos nombres se formaron y estuvieron en uso" (Koch 2003: 201).

No caso que nos ocupa neste trabalho, é evidente que Tartessos adquire significados muito diversificados consoante o autor que menciona este nome. Este-

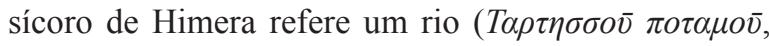
$P M G$ 184; Str. 3.2.11), conduzindo à associação posterior com o Bétis ou Guadalquivir (Str. 3.2.11). Por seu turno, a paisagem onde habitava Gérion, Erítia (cf. Hes., Th. 289ss.), foi muitas vezes identificada com Gadir (Álvarez 2007, 2009: 90, cf. Albuquerque 2010).

A esta primeira referência acrescenta-se a de um aparente território político, com o texto de Anacreonte, numa célebre frase transmitida por Estrabão (3.2.14): "No quisiera yo ni el cuerno de Amaltea ni ser rey de Tarteso ciento cincuenta años". A presença de $\beta \alpha \sigma l \lambda \varepsilon \tilde{\sigma} \sigma \alpha l$ ("reinar"/“governar") permite pensar na existência desse espaço político sobre o qual o poeta podia ter escutado algo, na medida em que viveu na corte de Polícrates de Samos por volta de 536-522 a.C. (Gangutia 1998: 125). Este dado permitiria relacionar o texto de Anacreonte com a viagem de Colaios, relatada por Heródoto (IV, 152), mas a referência a um $\beta \alpha \sigma i \lambda \varepsilon v$ c surge na tradição transmitida pelos Foceenses (idem. I.153) e não naquela. No entanto, o excerto de Anacreonte não permite verificar se se trata de um topónimo ou de uma região que pode ter como base de designação a bacia do rio, ou vice-versa. Devemos assinalar, porém, que o caráter vago das informações pode indicar uma certa familiaridade do nome (e do seu significado) entre a audiência destes autores, dispensando a exposição de pormenores.

A posterior referência de Hecateu de Mileto assinala um corónimo por duas vezes, relacionando-o com duas cidades: "Elibirge, cidade de Tartessos" e "Ibila, cidade da Tartéssia", a última das quais tinha minas de prata e ouro (THA IIA 23.I).

As duas passagens herodotianas que referem Tartessos introduzem, no contexto que tem vindo a ser tratado ao longo destas linhas, questões interessantes. $\mathrm{O}$ primeiro desses relatos (1.163), transmite a viagem dos Foceenses, que "depois de chegarem a Tartessos, travaram amizade com o rei local, chamado Argantónio, que aí reinou durante oitenta anos e viveu, ao todo, cento e vinte" (Trad. J.R. Ferreira e M.F. Silva). A tradução

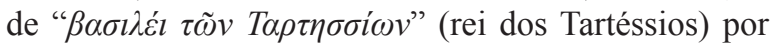
"rei local" afasta a possibilidade de reconhecer o nome

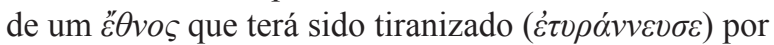
Argantónio. Embora o termo $\varepsilon \theta^{\prime} v o \varsigma$ não apareça neste

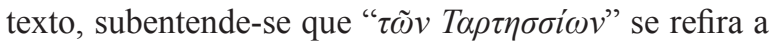

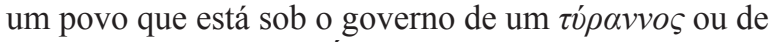
um $\beta \alpha \sigma i \lambda \varepsilon v ́ \varsigma$ (1.53.2). É C.P. Jones (1996: 316) quem assinala este pormenor, embora não se refira a 1.163. Estabelecer-se-ia aqui uma relação com o texto de Anacreonte, complementada com a referência a um território dominado?

O nome Tartéssios pode significar, simplesmente, "habitantes de Tartessos", segundo se depreende da sequência geográfica da viagem dos foceenses, na qual 
parece surgir um corónimo (Álvarez 2009: 92). Porém, em 4.152, Heródoto refere Tartessos como um "porto

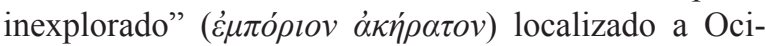

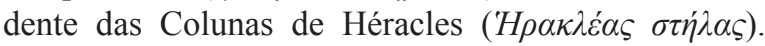
Este texto, quando comparado com o anterior, levanta algumas dúvidas relativamente à dependência do autor em relação aos seus informadores, uma vez que, para os Foceenses, Tartessos seria um corónimo e, para os Sâmios, um porto. No entanto, podemos colocar um ponto de interrogação sobre o relato de Hdt. 1.163: é possível que Tartessos seja uma cidade integrada na designação de Ibéria, uma vez que desempenha um papel decisivo na narrativa como última etapa da viagem que antecede a concretização do seu objetivo.

Esta última ideia pode ser contrastada com um texto de Herodoro, escrito em finais do séc. V, onde surge o etnónimo "Tartéssio" numa sequência de cariz periegético. O texto, transmitido e introduzido por Constantino Porfiriogénito, refere Ibéria como um território dividido em muitos povos ( $\pi 0 \lambda \lambda \alpha \dot{\varepsilon} \varepsilon \theta \theta v \eta$, Const. Porph., Adm. Imp. 23; THA IIA, 46). A transcrição revela, porém, que estes $\check{\varepsilon} \theta v \eta$ são representados por Herodoro como $\varphi \tilde{v} \lambda \alpha$ (tribos): Cinetes, Gletes, Tartéssios; Elbissínios, Mastienos e Celcianos. Estas “tribos”, por sua vez, pertencem a uma mesma entidade ( $\gamma \varepsilon ́ v o \varsigma)$ que pode ser traduzida por "povo", embora com a provável conotação genética que foi anteriormente apontada. Em que se baseia Herodoro para enquadrar estas $\varphi \tilde{v} \lambda \alpha$ num

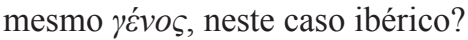

De todo o panorama apresentado, destaca-se a representação de uma entidade com contornos vagos e até mesmo contraditórios. Entre o testemunho de Anacreonte e o de Heródoto estaria o de Hecateu, que assinala um território no qual existiriam cidades, mas este autor não refere qualquer $\pi \delta ́ \lambda \iota \varsigma$ ou $\varepsilon \dot{\mu} \mu \pi o ́ \rho ı o v$ com esse nome.

Em todo o caso, para admitir a existência de um Ě $\theta v o \varsigma$ Tartéssio indígena, torna-se necessário assinalar um acontecimento que tenha provocado uma necessidade de coesão perante a ameaça de um elemento externo. Os sentimentos de pertença, compósitos e cambiantes, podem condicionar a formação de Spirit Provinces ou, para recorrer à expressão de B. Anderson, de "comunidades imaginadas". Estas circunstâncias históricas podem não ser percetíveis através do registo arqueológico. No entanto, a valorização das necrópoles e dos santuários como marcadores territoriais e, consequentemente, como elementos fundamentais para a coesão identitária, pode ser útil para uma aproximação à formação de sentimentos de pertença capazes de integrar indivíduos com origens diversas ou, por outro lado, refletir os resultados de uma desestruturação prévia do território indígena.

Este papel pode ter sido detido pelo santuário de Gadir, dedicado a Melqart, e por outros, convertendo o episódio de fundação num património comum dominado pelo agente oriental, aglutinador de vários sentimentos de pertença. Não deixa, por isso, de suscitar alguma perplexidade a ausência de relação entre Fenícios e Tartessos quando estas fontes, cronologicamente situadas entre os séculos VII e V a.C., são contemporâneas de um processo de ocupação consolidado e provavelmente regido por uma identidade própria, embora ligada aos fundadores Tírios (López 2004, Álvarez e Ferrer 2009).

Vimos também que um č́vos pode ser uma entidade multifacetada e compósita, suficientemente abrangente para incluir diversas subdivisões, cada qual com uma possível identidade própria. Quer isto dizer que a designação de um $̌$ č $\theta$ vo s pode derivar do nome genérico que é utilizado por um grupo dominante, o que parece notório no caso dos Citas de Heródoto (4.5-11).

Esta questão pode ir para além da materialidade, uma vez que a utilização de um determinado ritual ou objeto pode representar uma apropriação do elemento externo que não compromete a identidade de grupo. No entanto, a organização de um território em torno de um marcador (p.ej., santuário) pode resultar na restruturação de identidades partilhadas e ser um veículo eficaz na transmissão e receção da ideologia oriental. Seria necessário, porém, conhecer com rigor os aspetos que se transformaram, como, porquê e com que objetivo (p.ej., Belén e Escacena 1995, Belén 2001: 37). É por este motivo que creio que uma análise que valorize a relação entre marcadores territoriais e identidade pode assinalar situações de coexistência pacífica, domínio, desmantelamento das estruturas preexistentes, etc.

A questão da construção de identidades através do registo escrito é complexa, mas não o é menos quando o nosso olhar se dirige para o registo arqueológico. A materialidade nem sempre é um reflexo de etnicidade, mas em determinados casos, pode exprimir um modo de garantir a sobrevivência (cultural) de um grupo humano ou transmitir as senhas de identidade de um grupo social, seja ele dominante ou não. As perspetivas que canalizam as observações para o lado indígena (p.ej. Torres 2002), destacam o papel do autóctone na construção da sua própria identidade e da sua própria história. É neste sentido que creio que Tartessos é, no essencial, uma entidade mista que integra indivíduos de origens muito diversificadas sob uma mesma designação. Falta saber, porém, se este nome deriva da 
observação externa (neste caso, grega) ou se se trata de um nome criado e assumido num território localizado a Ocidente das Colunas de Héracles (cf. Álvarez 2007 para a associação entre Tartessos e Gadir).

Há que assinalar, finalmente, que a distribuição dos espaços de culto no Baixo Guadalquivir, analisada com esta perspetiva, parece indicar a existência de vários territórios políticos ou "províncias espirituais" e não apenas de um. Este tema será desenvolvido noutra ocasião.

É momento de terminar este texto. Pretendi apresentar alguns pontos de interrogação sobre a complexidade da construção de identidades, com base em elementos tão (aparentemente) díspares como o registo material, o registo escrito e alguns estudos sobre a História de África. Embora possamos identificar as diferenças entre o conteúdo de cada uma destas "fontes", todas elas colocam problemas comuns que contribuem para a elaboração de um questionário que permita lançar um outro olhar sobre a "questão tartéssica".

\section{ABREVIATURAS}

As abreviaturas das fontes clássicas baseiam-se em Greek - English Lexicon (H.G. Liddell e R. Scott 1958) e Oxford Latin Dictionary (P.G.W. Glare, $2^{\mathrm{a}}$ ed. 2012).

Arist., Pol.: Aristóteles, Política; Const. Porf.: Constantino Porfiriogénito; E., Ph.: Eurípides, As Fenícias; Hdt.: Heródoto; Hes., Th.: Hesíodo, Teogonia; J., Ap.: Flávio Josefo, Contra Apião; Pl., Mx.: Platão, Menexeno; Plb.: Políbio; Plu.: Plutarco; PMG: Poetae Melici Graeci (D.L. Page); Sil.: Sílio Itálico, As Guerras Púnicas; Str.: Estrabão; Th.: Tucídides; THA: Testimonia Hispaniae Antiquae (J. Mangas e D. Plácido, dirs.); X., HG: Xenofonte, Historia Graeca (Helénicas)

\section{BIBLIOGRAFIA}

Albuquerque, P. (2008): “Camões e Tartessos: leituras em torno de dois excertos d'Os Lusíadas". Spal 17: 137168. http://dx.doi.org/10.12795/spal.2008.i17.07

Albuquerque, P. (2010): Tartessos: entre Mitos e Representações. Cadernos da Uniarq 6. Lisboa, Universidade de Lisboa.

Álvarez Martí-Aguilar, M. e Ferrer Albelda, E. (2009): "Identidad e Identidades entre los fenicios de la Península Ibérica en el periodo colonial", en F. Wulff Alonso e M. Álvarez Martí Aguilar (eds.), Identidades, culturas y territorios en la Andalucía Prerromana, pp. 165-204.
Málaga e Sevilla, Universidad de Málaga y Universidad de Sevilla.

Álvarez Martí-Aguilar, M. (2005): Tarteso. La construcción de un mito en la historiografía española. Málaga, CEDMA.

Álvarez Martí-Aguilar, M. (2007): “Arganthonius Gaditanus. La identificación de Gadir y Tartessos en la tradición antigua". Klio 89(2): 477-492.

Álvarez Martí-Aguilar, M. (2009): "Identidad y Etnia en Tartessos". Arqueología Espacial 27: 79-111.

Amselle, J.L. e M'Bokolo, E. (1999): Au coeur de l'Ethnie. Anthropologie de l'Identité en Afrique et ailleurs. Paris, Payot.

Amselle, J.L. (1987): “L'ethnicité comme volonté et comme représentation: à propos des Peuls du Wasolon". Annales (ESC), 42e année 2, pp. 465-489.

Amselle, J.L. (1990): Logiques métisses. Anthropologie de l'identité en Afrique et ailleurs. Paris, Payot.

Arruda, A.M. (2010): "Fenícios no território actualmente português: e nada ficou como antes", en M.L. de la Bandera Romero e E. Ferrer Albelda (coords.), El Carambolo. 50 años de un tesoro, pp. 439-452. Sevilla, Universidad de Sevilla.

Batty, R. (2000): "Mela's Phoenician Geography". Journal of Roman Studies 90: 70-94.

Belén, M. e Escacena, J.L. (1995): "Interacción cultural fenicios-indígenas en el Bajo Guadalquivir". Kolaios 4: 67-101.

Belén, M. (2001): “La cremación en las necrópolis tartésicas", en R. García Huerta e J. Morales Hervás (eds.), Arqueología funeraria: las necrópolis de incineración, pp. 37-78. Cuenca, Ediciones de la Universidad de Castilla-La Mancha.

Bentley, G.C. (1997): "Ethnicity and practice". Comparative Studies in Society and History 29 (1): 24-55.

Bernal, M. (1993): Atenea Negra. Las raíces afroasiáticas de la civilización clásica, Vol. I, "La invención de la Antigua Grecia”, pp. 1785-1985. Barcelona, Crítica.

Bertrand, J.M. (2005): “Génos”, en J. Leclant (dir.), Dictionnaire de l'Antiquité, p. 954. Paris, PUF.

Black, J. (1997): Maps and History. Constructing images of the Past. New Haven, London, Yale University Press.

Bonnet, C. (2010): "Astarté en Méditerranée. Reflections sur une identité une et plurielle”, en M.L. de la Bandera e E. Ferrer (coords.), El Carambolo. 50 años de un tesoro, pp. 453-463, Sevilla, Universidad de Sevilla. 
Bordreuil, P. e Ferjaoui, A. (1988): “A propos des "Fils de Tyr" et des "Fils de Carthage". Studia Phoenicia 6: 137-142.

Bühnen, S. (1992): "Place names as an historical source: an introduction with examples from Southern Senegambia and Germany". History in Africa 19: 45-101.

Cabanes, P. (2005): "Éthnos", en J. Leclant (dir.), Dictionnaire de l'Antiquité, p. 850. Paris, PUF.

Cardete del Olmo, M.C. (2004): "Ethnos y Etnicidad en la Grecia Clásica", en G. Cruz Andreotti e B. Mora Serrano (eds.): Identidades étnicas-identidades políticas en el mundo prerromano hispano, pp. 17-29. Málaga, CEDMA.

Castro Martínez, P.V. e González Marcén, P. (1989): "El concepto de frontera: Implicaciones teóricas de la noción de territorio político". Fronteras. Arqueología Espacial 13, pp. 7-18.

Chantraine, P. (1968): Dictionnaire étymologique de la langue grecque: Histoire des mots. Paris, Klincksieck.

Crowley, E.L. (1993): Contracts with spirits: Religion, Asylum and Ethnic Identity in the Cacheu region of Guinea-Bissau [fac-simil]. Michigan, UMI Dissertations/ A Bell e Howell Company [texto original policopiado, 1990].

Cruz Andreotti, G. e Mora Serrano, B. (eds.) (2004): Identidades étnicas-identidades políticas en el mundo prerromano hispano. Málaga, CEDMA.

Cruz Andreotti, G. (2010): "Tarteso-Turdetania o la deconstrucción de un mito identitario”, en M.L. de la Bandera Romero e E. Ferrer Albelda (coords.), El Carambolo. 50 años de un tesoro, pp. 17-52. Sevilla, Universidad de Sevilla.

Dias, J.R. (1999): "Identidade". Verbo. Enciclopédia Luso-brasileira de Cultura, Vol. 10, pp. 813-814. Lisboa e São Paulo, Verbo.

Díes Cusí, E. (2001): "La influencia de la arquitectura Oriental fenicia en las arquitecturas indígenas de la Península Ibérica (s. VIII-VII)", en D. Ruiz Mata e S. Celestino Pérez (eds.), Arquitectura oriental y orientalizante en la Península Ibérica, pp. 69-122. Madrid, CSIC.

Dubuisson, M. (2001): "Barbares et barbarie dans le monde gréco-romain: du concept au slogan”. L'Antiquité classique 70: 1-16.

Dubuisson, M. (1982): "Remarques sur le vocabulaire grec de l'acculturation”. Revue Belge de Philologie et d'Histoire 60(1): 5-32.

Escacena Carrasco, J.L. (1992): “Indicadores étnicos en la Andalucía prerromana". Spal 1: 321-344. http://dx.doi.org/10.12795/spal.1992.i1.16
Escacena Carrasco, J.L. (2001): "Fenicios a las puertas de Tartessos". Complutum 12: 73-96.

Escacena Carrasco, J.L. (2011): "Variación identitaria entre los orientales de Tartessos. Reflexiones desde el antiesencialismo darwinista", en M.A. Martí Aguilar (ed.), Fenicios en Tartessos: nuevas perspectivas, pp. 161-192. Oxford, BAR International Series.

Estermann, C. (1983): Etnografia de Angola (Sudoeste e Centro). Colectânea de artigos dispersos, coligidos por G. Pereira e apresentados por M.V. Guerreiro, Vol. I. Lisboa, Instituto de Investigação Científica Tropical.

Fernández Götz, M.A. (2009): “La etnicidad desde una perspectiva arqueológica: propuestas teórico-metodológicas". Espacio, Tiempo y Forma, serie II, Historia Antigua 22, pp. 187-199.

Gangutia Elícegui, E. (1998): La Península Ibérica en los autores griegos: de Homero a Platón, en J. Mangas e D. Plácido (eds.), Testimonia Hispaniae Antiqua, IIA. Madrid, Editorial Complutense.

García Calvo, A. (2009): "Identidad", en R. Reyes (dir.), Diccionario crítico de Ciencias Sociales, pp. 1497-1504. Madrid, Plaza y Valdés.

García Fernández, F.J. (2007): "Etnología y Etnias de la Turdetania en época Prerromana". Cuadernos de Prehistoria de la Universidad Autónoma de Madrid 33: 117-143.

García Martínez, A. (2004): "A vueltas con la etnicidad: ¿de qué sirve el concepto de "etnía”?" Educatio 22: 139-156.

Gaulmier, J. (1981): "Poison dans les veines. Note sur le thème du sang chez Gobineau". Romantisme 31: 197-208.

Gonçalves, A.C. E Barata, O. (1999): "Grupos étnicos”. Verbo: Enciclopédia Luso-Brasileira da Cultura, Vol. 13, pp. 1311-1313. Lisboa y S. Paulo, Verbo.

González Wagner, C. (2000): “Santuarios, territorios y dependencia en la expansión fenicia arcaica en occidente". Arys 3: 4-58.

González Wagner, C. (2005): "Fenicios en el Extremo Occidente. Conflicto y violencia en el contexto colonial arcaico". Revista Portuguesa de Arqueologia 8(2): 177-192.

Gruzinski, S. e Bernand, C. (2007): Histoire du Nouveau Monde, vol. II, Les Métissages. Paris, Fayard.

Gruzinski, S. (1999): La pensée métisse. Paris, Fayard.

Heintze, B. (2007): Angola nos séculos XVI e XVII. Estudos sobre Fontes, Métodos e História. Luanda, Kilombelombe.

Hernando, A. (2002): Arqueología de la Identidad. Madrid, Akal. 
Hillmann, K.-H. (2001): Diccionario enciclopédico de Sociología, fundado por Günter Hartfiel [ed. Or. 1994]. Dir. da edição espanhola por A. Martínez Riu. Barcelona, Herder.

Horta, J.S. (2009): "Ser "Português" em terras africanas: vicissitudes da construção identitária na "Guiné do Cabo Verde" (sécs. XVI-XVII)", en H. Fernandes et al. (eds.), Nação e Identidades. Portugal, os portugueses e os outros, pp. 261-274. Lisboa, Centro de História da Faculdade de Letras de Lisboa/ Caleidoscópio.

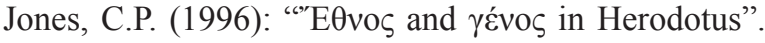
Classical Quaterly 46 (2): 315-320.

Jones, S. (1997): The Archaeology of Ethnicity. Constructing identities in past and present. London y New York, Routledge.

Jones, S. (2008): "Ethnicity: Theoretical approaches, methodological implications", en R.A. Bentley, H.D.G. Machner e C. Chippdale (eds.), Handbook of Archaeological Theories, pp. 321-333. Lanham, Altamira Press.

Knapp, A.B. (2008): Prehistoric and Protohistoric Cyprus. Identity, Insularity, and connectivity. Oxford, Oxford University Press.

Koch, M. (2003): Taršiš e Hispania. Madrid, CEFYP.

Lalanda, P. (2005): “A identidade é sempre uma relação. Uma introdução ao uso do conceito de identidade". Actas das III jornadas/ Congresso do Arquivo de Beja, I: 39-42. Beja: Câmara Municipal de Beja.

López Castro, J.L. (2004): "La identidad étnica de los fenicios occidentales", en G. Cruz Andreotti e B. Mora Serrano (eds.), Identidades étnicas-identidades politicas en el mundo prerromano hispano: 149-167. Málaga, CEDMA.

López Ruiz, C. (2005): "Revisión crítica de la aparición de Tartessos en las fuentes clásicas y semíticas", en S. Celestino Pérez e J. Jiménez Ávila (eds.), El Periodo Orientalizante. Actas del III Simposio Internacional de la Arqueología de Mérida: Protohistoria del Mediterráneo Occidental. Anejos de Archivo Español de Arqueología XXV: 347-362. Mérida, CSIC.
Moreno Arrastio, F.J. (1999): "Conflictos y perspectivas en el periodo precolonial tartésico". Gerión 17: 149-177.

Moret, P. (2004): "Ethnos ou Ethnie? Avatars anciens et modernes des noms des peuples ibères", en G. Cruz Andreotti e B. Mora Serrano (eds.), Identidades étnicas-identidades políticas en el mundo prerromano hispano, pp. 32-62. Málaga, CEDMA.

Niculescu, G.A. (1997-1998): “The material dimension of ethnicity", New Europe College Yearbook 19971998, pp. 203-262.

Nordman, D. (2005): "Identidades territoriales", en P. Boissinot e P. Rouillard (coords.), Lire les territoires des sociétés anciennes. Dossier des Mélanges de la Casa Velázquez, Nouvelle série 35(2), pp. 147-157.

Potolsky, M. (2006): Mimesis. London, New York, Routledge.

Powell, J.E. (1938): A Lexicon to Herodotus. Cambridge, C.U.P.

Ruby, P. (2006): "Peuples, fictions? Ethnicité, identité ethnique et sociétés anciennes". Revue des Études Anciennes 108 (1): 25-60.

Sanmartín, J. (1994): “Toponimia y antroponimia: Fuentes para el estudio de la cultura púnica en España", en A. González Blanco; J.L. Cunchillos Ilarri e M. Molina Matos (coords.), El mundo púnico. Historia, sociedad y cultura, pp. 227-247. Murcia, Editora Regional de Murcia.

Soares, C. (2003): A Morte em Heródoto. Valores universais e particularismos étnicos. Lisboa, Fundação Calouste Gulbenkian.

Sousa, R. e Santos, A.S. (2010): "A incidência do Anticastelhanismo na Literatura Portuguesa". Letras Comvida 1: 141-154.

Terén, E. (2002): "La etnicidad y sus formas: aproximación a un modelo complejo de pertenencia étnica". Papers 66: 45-57.

Twiesselmann, F. (1971): “ La méthodologie du métissage". Bulletins et mémoires de la Société d'Anthropologie de Paris, XIIe Série 7(2): 145-157. 